\title{
DanUtA KaBAT-RUDNICKA
}

Uniwersytet Kardynała Stefana Wyszyńskiego

\section{PRAWO RZYMSKIE A EUROPEJSKA TRADYCJA PRAWNA}

\begin{abstract}
"Nicht darin besteht die Bedeutung des römichen Rechts für die moderne Welt, daß es vorübergehend als Rechtsquelle gegolten... sondern darin, daß es eine totale innere Umwandlung bewirkt, unser ganzes juristisches Denken umgestaltet hat. Das römiche Recht ist ebenso wie das Christenthum ein Culturelement der modernen Welt geworden".
\end{abstract}

\section{UWAGI WSTĘPNE}

Prawo jest częścią kultury. Wśród wszystkich wspólnych wartości, idei i zasad poczesne miejsce zajmuje prawo, mechanizmy jego tworzenia i stosowania. Kultura rzymska, a w szczególności wpływ prawa rzymskiego na współczesne prawo w Europie, to także jeden z podstawowych elementów integracji europejskiej. Warto podkreślić szczególną rolę jaka przypadła prawu w konstytuowaniu Unii Europejskiej (wcześniej Wspólnot Europejskich). Tradycja prawa rzymskiego mo-

${ }^{1}$ R. vON JHERING, Geits des römischen Rechts auf den verschiedenen Stufen seiner Entwicklung ${ }^{6}$, Leipzig, 1907, s. 1 i n. 
gła być upowszechniana na gruncie europejskim dzięki zachowanej spuściźnie pisemnej oraz atrakcyjności i sile oddziaływania kultury rzymskiej i języka łacińskiego - dawnej lingua franca - które dyktowały przez wiele pokoleń kanony edukacyjne, zarówno w sferze kościelnej jak i świeckiej. Ponadto model prawa rzymskiego ze względu na swą logiczną konstrukcję dobrze odpowiadał prawidłom ludzkiego rozumowania, albowiem prawo rzymskie było z natury racjonalne i spójne intelektualnie. Inną równie ważną cechą charakterystyczną jest m.in. to, że prawo europejskie opiera się na wartościach, które sytuują osobę ludzką w centrum uwagi, czyniąc z niej podmiot i zarazem punkt intelektualnego odniesienia, co zawdzięczać należy rozumieniu zasady wolności w prawie rzymskim.

\section{Prawo RzymSKIE}

Prawo rzymskie miało swój przemożny wpływ na kształtowanie się świata Zachodu, narodów i systemów prawnych, dostarczając racjonalnych podstaw systemu oraz wpajając poczucie legalizmu ${ }^{2}$. Prawo rzymskie legło u podstaw wielu współczesnych rozwiązań i instytucji prawnych, zaś tym co jest dla niego najbardziej charakterystyczne jest m.in.: wysoce rozwinięta jurysprudencja, innymi słowy szczególna wiedza rozwijana i utrwalana przez prawników, rzec można, wyjątkowa w świecie klasyczno-antycznym; oddzielenie prawa od religii, moralności, polityki i ekonomii, to jest oddzielenie tego co prawne od tego co nieprawne; szczególny nacisk kładziony na prawo prywatne, i tym samym na procedurę cywilną (prawo karne i zarządzanie sprawami państwa wydają się nie być uważane przez prawników rzymskich za podlegające kryteriom prawnym). Dodać należy, że rzymskie prawo prywatne, będące prawem prawników (Juristenrecht), nie zostało zre-

2 Przykładowo rozwiązywanie konfliktów społecznych i ekonomicznych, nie tylko i wyłącznie przy użyciu siły, autorytetu i kompromisu, lecz przy zastosowaniu ogólnych wykoncypowanych reguł, stanowiących charakterystyczną cechę zachodniego myślenia prawnego, stało się możliwe dzięki prawu rzymskiemu. Zob. F. WIEACKER, The Importance of Roman Law for Western Civilization and Western Thought, «B. C. Int'l \& Comp. L. Rev.» 4.2/1981, s. 257. 
dagowane systematycznie i wszechstronnie w ustawach, lecz było stosowane i rozwijane przez prawników posiadających duże praktyczne doświadczenie. To z kolei pozwala zrozumieć realizm prawa rzymskiego i koncentrowanie się na rozwiązywaniu problemów praktycznych, zaś pojawiające się kontrowersje odzwierciedlają wewnętrzną dynamikę prawa rzymskiego.

Odwoływanie się do samego tylko prawa rzymskiego jest niewystarczające, ponieważ nawet prawo rzymskie okresu klasycznego konstytuowało wcześniejszą tradycję obejmującą wiele pokoleń prawników. Prawo rzymskie, mające złożony charakter, z natury swej kazuistyczne, rozwijało się przez wiele wieków, opierając się na dwóch koncepcyjnie i historycznie oddzielnych tradycjach: prawa cywilnego (ius civile), obejmującego zwyczajowy rdzeń reguł prawnych stosowanych w odniesieniu do obywateli rzymskich oraz ius honorarium (ius praetorium) $)^{3}$, utożsamianego z zasadą słuszności, wprowadzanego przez praetora $\mathrm{w}$ interesie publicznym po to, by pomagać, uzupełniać i korygować tradycyjne prawo cywilne. Jednakże pomimo całej swej złożoności, prawo rzymskie było przejrzyste z racji swej logicznej konstrukcji i nie zmieniło się w niemożliwy do opanowania gąszcz szczegółów, ponieważ prawnicy rzymscy wypracowali dużą ilość koncepcji prawnych, reguł i instytucji, które starali się ustawicznie koordynować i intelektualnie wiązać ze sobą, tworząc tym samym rodzaj otwartego systemu, który łączył zwartość logiczną ze znacznym stopniem elastyczności. W procesie tym prawnicy rzymscy kierowali się podstawowymi wartościami, albo inaczej mówiąc zasadami, takimi jak: wolność, bona fides, humanitas oraz ochrona praw (w tym praw nabytych), w szczególności zaś ochrona prawa własności. Natomiast

${ }^{3}$ W literaturze przedmiotu spotykamy się również z trójpodziałem na ius civile inaczej ius Quiritium, charakteryzujące się formalizmem i silnym związkiem z religia, ius gentium wykorzystywane w obrocie (gospodarczym), bowiem pozbawione było formy i tym samym było łatwe w stosowaniu oraz ius praetorium, inaczej ius honorarium, prawo praetorskie mające na celu wspieranie, korygowanie i uzupełnianie prawa cywilnego dla pożytku publicznego, jak trafnie powiedział Papinian "ius praetorium est, quod praetores introduxerunt adiuvandi vel supplendi vel corrigendi iuris civilis" (D. 1,1,7,1). Zob. H. KuPISZEWsKI, Prawo rzymskie a wspótczesność, Warszawa 1988, s. 19-21. 
tym co czyniło rzymską jurysprudencję szczególnym przedmiotem analizy był fakt, że powody podjęcia określonej decyzji nie były podawane w ogóle (niekiedy jedynie będąc sugerowane), przez co prawo rzymskie było szczególnie bogate w milczące założenia, które mogły zostać ujawnione $\mathrm{w}$ procesie interpretacji ${ }^{4}$.

Warto też zauważyć, że w przypadku prawa rzymskiego mamy do czynienia z wyjątkowymi instytucjami, przy czym źródłem owej wyjątkowości jest tradycjonalizm, realizm oraz autorytarna postawa rzymskich nobilitas. Rzym był pierwszą polity, która rozwinęła wysoce zobiektywizowaną procedurę arbitrażowa, po to by móc rozwiązywać konflikty społeczne i gospodarcze. Rzeczony rozwój uwolnił rzymski system prawny od archaicznych rytuałów, z drugiej zaś strony pozwalał na pozostawanie wolnym od wpływów szybko zmieniających się ideologii politycznych i moralnych, i to właśnie stanowi - zdaniem niektórych - najważniejszy wkład do zachodniej myśli prawniczej. Tak więc, udział prawa rzymskiego w rozwoju zachodniej myśli prawniczej to przede wszystkim wysoce zobiektywizowane metody rozwiązywania konfliktów, nie zaś odkrywanie koncepcji prawa jako takiego, ani też redukcja prawa do ogólnych warunków i do zasady sprawiedliwości ${ }^{5}$.

III. Prawo Kontynentalne ( CIVIL LAW) a PRAWO ANGLOAMERYKaŃSKIE (COMMON LAW)

Niezależnie od odrębnych dróg rozwoju, te dwa wielkie systemy prawne świata zachodniego łączył element racjonalizmu. Z jednej strony mamy do czynienia z systemami prawnymi kontynentu europejskiego i Ameryki Łacińskiej, które zasadniczo charakteryzują wielkie kodyfikacje, to jest kodeksy łacińskie oparte na kodeksie Napoleona oraz kodeksy Europy Środkowej (Austrii, Niemiec i Szwajcarii) i ich

${ }^{4}$ R. Zimmermann, Roman Law and Legal Culture, «NZ Law Review» 31.2/2007, S. 357-359.

${ }^{5}$ F. WIEACKER, The Importance..., s. 264-265. 
naśladownictwa w innych $\mathrm{krajach}^{6}$. Z drugiej strony common law, prawo krajów anglosaskich, które charakteryzuje wyjątkowy system sądów, w którym pomimo rosnącego znaczenia prawa stanowionego, nadal dominuje prawo oparte na wiążących precedensach ${ }^{7}$.

W przypadku prawa precedensowego, w szczególności zasada słuszności wywodzi się - o ile nie całkowicie to przynajmniej częściowo z prawa rzymskiego. W Stanach Zjednoczonych na uwagę zasługuje także zaakceptowanie nowoczesnej, czytaj zsekularyzowanej i racjonalnej formy prawa natury wczesnego okresu oświecenia, prawa, które legło u podstaw amerykańskiej teorii konstytucyjnej ${ }^{8}$. Ponadto, o ile w systemach skodyfikowanych rzymskie prawo cywilne nie jest bezpośrednio stosowane $\mathrm{w}$ sądach, to w systemach nieskodyfikowanych zdarza się, że teksty prawa rzymskiego są cytowane jako egzemplum ogólnych zasad prawa9.

\section{EUROPEJSKA KULTURA PRAWNA}

Europejska kultura prawna nie jest jedyna i wyjątkowa w skali światowej, i zarówno w odniesieniu do przeszłości jak i teraźniejszości pamiętać należy, że Europejczycy nie mają monopolu na polu kultury prawnej. Istnieje przecież wiele innych kultur prawnych, często dużo starszych, które rozwinęły się na innych kontynentach ${ }^{10}$, przy czym należy zauważyć, że kultury prawne zarówno Indii jak i Chin wydają się zmierzać w podobnym kierunku, tj. racjonalizacji i profesjonalizacji prawa.

${ }^{6} \mathrm{~W}$ Stanach Zjednoczonych, gdzie przeważa tradycja prawa precedensowego, także spotykamy się z prawem skodyfikowanym, a jest nim kodeks stanu Luizjana.

7 F. WIEACKer, The Importance..., s.258.

8 Tamże, s. 260.

9 Zob. P. Stein, Roman Law in European History, Cambridge 2004, s. 128, gdzie autor przytacza sprawę sądową z 1987 r., w której sędzia angielski zastosował zasadę prawa rzymskiego, a chodziło o confusio.

${ }_{10}$ Zob. Główne kultury prawne wspótczesnego świata, red. H. Roт, Warszawa 1995. 
Zakłada się, że niezależnie od wielu historycznych, społecznych i ideologicznych różnic, europejska kultura prawna tworzy zarówno historyczną jak i egzystencjalną jedność - wyróżniającą się z wszystkich pozostałych zarówno rozwiniętych jak i plemiennych kultur prawnych. Jednakże do wąskiego rozumienia zachodnioeuropejskiej kultury prawnej (kontynentalnej) należy dodać common law, a także prawo państw Europy Środkowo-Wschodniej ${ }^{11}$. Należy to uczynić, mając na względzie rzymskie korzenie, zasadniczo ze względu na wspomnianą już zasadę słuszności, która przynależy do ius utrumque, na które składają się zarówno elementy prawa kanonicznego jak i prawa rzymskiego. Co zaś do innych podobieństw, przybliżających common law do ius commune, albo inaczej mówiąc do prawa neo-rzymskiego ważne jest to, że oba systemy prawne pozostają co do zasady nieskodyfikowane. Co więcej, common law wywiera również wpływ na europejski, kontynentalny system prawny, m.in. na europejskie prawo kolizyjne, gdzie przyjęta została zasada zgodnie z którą prawo państwa, które posiada najbardziej istotny związek ze stronami umowy oraz z transakcją winno mieć zastosowanie - zasada zawarta w Second Restatement of Conflicts $^{12}$, zasada, która jest obecna nie tylko w kodyfikacjach niektórych państw europejskich lecz również w Convention on the law applicable to Contractual Obligations ${ }^{13}$. Angloamerykańskie dok-

${ }^{11}$ F. Wieacker, Foundations of European Legal Culture, «Am. J. Comp. L.», 38.1/1990, s. 6 i n.; zob. też rozważania na temat wpływu ius commune na Magna Carta R.H. Helmholz, Magna Carta and the Ius Commune, «U. Chi. L. Rev.», 66.2/1999, s. 297-372.

12 Restatement (Second) of Conflict of Laws (1969), Chapter 8. Contracts, Law governing in absence of effective choice by the parties, par. 1: "The rights and duties of the parties with respect to an issue in contract are determined by the local law of the state which, with respect to that issue, has the most significant relationship to the transaction and the parties under the principles stated ..." http://www.kentlaw. edu/perritt/conflicts/rest188.html zob. też: S.C. Symeonides, The Need for a Third Conflicts Restatement (and a Proposal for Tort Conflicts), «Indiana Law Journal» 75.2/2000, s. 437-474.

${ }^{13}$ Art. 4: „To the extent that the law applicable to the contract has not been chosen in accordance with Article 3, the contract shall be governed by the law of the country with which it is most closely connected". Convention on the law applicable to contractual 
tryny prawne wywierają także wpływ na stopniową unifikację prawa zobowiązań, m.in. na rozwiązania przyjęte w Vienna Convention on International Sale of Goods ${ }^{14}$, a także na prawo Unii Europejskiej, gdzie art. 101 TFUE (art. 85 TEWG) dotyczący praktyk antykonkurencyjnych, inkorporuje zasady amerykańskiego prawa antytrustowego.

U podstaw europejskiej kultury prawnej leży współistnienie, przeciwstawianie i godzenie różnych perspektyw: fides i ratio, papieża i imperatora, imperium i terytoriów konstytuujących, Rzymu i Bizancjum, klasycznej starożytności w wydaniu greckim i rzymskim, tradycji judeochrześcijańskiej, poczucia wolności a zarazem obowiązku, idei życia aktywnego i kontemplacyjnego, Chrystusa będącego Bogiem i człowiekiem, etc. Europa i kultura europejska są konstrukcjami historycznymi, kształtującymi się w wyniku stałego napięcia pomiędzy różnymi, często przeciwstawnymi tendencjami, jednością i różnorodnością, co z kolei tłumaczy dynamikę i rozwój kultury europejskiej ${ }^{15}$. Napięcie pomiędzy jednością i różnorodnością, charakterystyczne dla kultury europejskiej, ma również istotne znaczenie dla europejskiej tradycji prawnej, tradycji, która była kształtowana przez ius commune.

Do niezmiennych elementów europejskiej kultury prawnej należy: personalizm, legalizm oraz kierowanie się intelektem.

Pierwszy element kultury prawnej jakim jest personalizm ${ }^{16}$ odwołuje się do jednostki jako podmiotu, celu i intelektualnego punktu odniesienia. F. Wieacker twierdzi, że personalizm jest dziedzictwem wolnych państw obywatelskich - starożytnych polis, oraz stowarzyszeń tworzonych przez migrujące społeczności w okresie późnej starożytności oraz wczesnego średniowiecza ${ }^{17}$. Wolność i samostanowienie, zamiast magicznych i zbiorowych ograniczeń w kształtowaniu stosunków

obligations, wyłożona do podpisania w Rzymie 19 czerwca 1980 roku, weszła w życie 1 kwietnia 1991 roku (O.J. L 266, 09/10/1980).

${ }_{14}$ Sale of Goods (Vienna Convention) Act 1986 http://www.legislation.qld.gov.au/ LEGISLTN/CURRENT/S/SaleGoodVieA86.pdf
15 R. Zimmermann, Roman Law..., s. 345
16 Zob. też H. KupiszewsKi, op. cit., s. 5 i n.
17 F. WIEACKER, Foundations..., s. 20. 
prawnych, czy to w drodze kontraktu czy w oparciu o normy prawne, powinność zamiast przeznaczenia a tym samym odpowiedzialność za przestępstwa i czyny przestępne, kształtowały zachodnie wyobrażenie o prawie od czasów starożytnych, kształtując przede wszystkim pojęcie prawa prywatnego, jako wiązki subiektywnych uprawnień pomiędzy odpowiedzialnymi osobami ${ }^{18}$. Stałe napięcie pomiędzy indywidualistycznymi teoriami wolnościowymi a altruistycznym nauczaniem o odpowiedzialności, dostarczało podstaw dla rozwoju myśli prawniczej w Europie. Prawo klasyczne ograniczało pierwotną wolność w drodze kontraktu społecznego, który niekiedy jako konsensus, niekiedy jako kontrakt poddania lub panowania ustanawiał społeczną odpowiedzialność jednostek. Tak więc stały dialog pomiędzy teoriami wolnościowymi i odpowiedzialnością stał się wiodącym tematem wszystkich europejskich filozofii, zarówno prawnych jak i politycznych, mających istotne znaczenie dla zrozumienia prawa. Teorie wolnościowe umożliwiły ustanowienie: wolności posiadłości ziemskich, wolności sumienia, wolności gospodarczych, wolności politycznych oraz praw podstawowych, zawartych w nowożytnych konstytucjach. $\mathrm{Z}$ drugiej strony umowa społeczna lub też pakt dominacji legitymizował: suwerenność absolutnego monarchy z jego odpowiedzialnością za pokój, bezpieczeństwo, a nawet szczęście poddanych; demokratyczną suwerenność narodu będącą wyrazem volonté générale oraz kontrolę społeczeństwa socjalistycznego nad dystrybucją dóbr, możliwościami pracy i edukacji. Napięcie z jednej strony pomiędzy prawem własności i autonomią kontraktowania, a społecznymi ograniczeniami praw prywatnych i ich wykonywania z drugiej, są widoczne w prawie prywatnym nowoczesnych społeczeństw, zaś pojawiająca się antynomia pomiędzy liberalnym i społecznym państwem prawa stanowi jeden z podstawowych problemów konstytucyjnych w Europie ${ }^{19}$.

Drugim elementem europejskiej kultury prawnej jest legalizm, przez który należy rozumieć nie tylko i wyłącznie monopol ustawodawcy w kwestii tworzenia i dokonywania zmian w prawie, lecz także nakaz

\footnotetext{
18 Tamże, s. 21.

19 Tamże, s. 22.
} 
opierania decyzji regulujących stosunki społeczne oraz rozwiązywanie konfliktów w oparciu o zasady prawne, których ważność i akceptacja nie zależy od zewnętrznych, tj. moralnych, społecznych czy tez politycznych wartości lub celów. Warunkiem wstępnym dla zasady rządów prawa było - charakterystyczne zarówno dla rzymskiej jak i dla europejskiej jurysprudencji - oddzielenie systemu prawnego od reguł społecznych i innych jak: doktryny religijne, nakazy moralne, zwyczaje i konwencje. Rozdział o którym tutaj mowa, może być odnoszony do szczególnej, profesjonalnej administracji sądowej w starożytnym Rzymie, która prawdopodobnie wywodzi się od funkcji eksperckich wykonywanych przez rzymskich pontificies oraz spuściźnie tej jurysprudencji dla europejskiej nauki prawnej. W okresie późniejszym rozdział systemu prawnego od pozostałych reguł został ustanowiony na nowo, w drodze oddzielenia prawa od zasad moralnych, co skutkowało formalizmem i pozytywizmem nowoczesnego państwa konstytucyjnego. Tak więc rzeczony rozdział stanowi podstawę dla legalizmu, który przedstawia społeczne obowiązki, prawa i przywileje jako zobiektywizowane stosunki prawne, pozbawione arbitralności, caritas, empatii, jak również doraźnych celów danej sprawy. Legalizm odciążył również konflikty społeczne od siły, emocji, interesów i uprzedzeń. Legalizm zapewnił jednostce większą pewność prawa, zaś w procedurze karnej i cywilnej jednostka uzyskała znaczną wolność od arbitralności i irracjonalnej formy dowodu i postępowania, oraz więcej równości w sporze. Natomiast w prawie prywatnym legalizm prowadził od stanu do kontraktu, inaczej mówiąc przyznał jednostce autonomię by mogła kontrolować sferę osobistą jak i sferę własności, wolną od historycznych ograniczeń. Ogólnie rzecz ujmując legalizm był pierwszą i jedyną ideologią gwarantującą równość jednostek wobec Boga i natury, zmieniając historyczne prawa i przywileje w wolności, oraz w uniwersalne prawa człowieka. Legalizm umożliwił powstanie nowoczesnego państwa opiekuńczego, zmienił bowiem odpowiedzialność społeczeństwa wobec cierpiących niedostatek w konstytucyjną ochronę, przyjmującą formę podstawowych praw społecznych ${ }^{20}$. Należy nadto zauważyć, że

20 Tamże, s. 23-25. 
w systemach legalistycznych pojawia się antynomia pomiędzy ogólną i indywidualną sprawiedliwością, pewnością prawa i sprawiedliwością materialną, równością przed prawem i nierównością możliwości wyjściowych. A zatem konieczna jest korekta tego stanu rzeczy, przy czym to, co w starożytnym Rzymie czynił praetor w ramach dyskrecjonalnej władzy, w nowoczesnym ustawowym pozytywizmie czynią generalne klauzule i równoważenie interesów na drodze prawnej.

Trzecim stałym elementem europejskiej kultury prawnej jest kierowanie się intelektem, odnoszonym do sposobu w jaki rozumiane są sytuacje prawne, co z kolei ściśle wiąże się z tradycjami myślenia europejskiego. Oznacza to m.in. trwały udział filozofii greckiej w europejskiej kulturze prawnej, uczącej rzymskich jurystów, następnie zaś ich spadkobierców w całej Europie, formułowania pojęć oraz punktów wyjściowych dla ogólnej systematyzacji zjawisk prawnych. Począwszy od wczesnego okresu ery nowożytnej wypracowano zintegrowany system prawa kierującego się racjami rozumu, dając tym samym podstawy pod nowoczesne kodyfikacje, czego ostatecznym rezultatem były kodyfikacje, doktrynalne systemy nauki nowoczesnego prawa prywatnego oraz rewizja ogólnej teorii prawa. Zmianie uległo również rozumienie kwestii sprawiedliwości (od kładzenia nacisku na właściwe zachowanie publiczne do intelektualnego osądu na temat prawdy). Z kolei czynnik ideologiczny przez większość czasu działał jako progresywny, tj. wyrównawczy i emancypacyjny element $\mathrm{w}$ procesie rozwoju prawa europejskiego ${ }^{21}$.

\section{Prawo RZYMSKIE DZIŚ}

Jednym z powodów dla których prawo rzymskie miało tak duży wpływ na średniowieczną Europę było m.in. to, że zostało zredagowane w formie pisemnej, było zatem ratio scripta, co więcej pozostawało $\mathrm{w}$ zgodzie z rozumem, jako racjonalne i spójne intelektualnie, zaś szczególny charakter źródeł prawa rzymskiego zapobiegał nieelastyczności i statyczności systemu. Podobnie też prawo europejskie, które

${ }^{21}$ Tamże, s. 25-27. 
jest poddawane stałej adaptacji, reaguje na zmieniające się okoliczności i nowe sytuacje, wykazując niezwykłą zdolność do integracji, przy czym cechą charakterystyczną prawa europejskiego jest to, że jest ono wyuczoną profesją, wolnym zawodem, zaś rozwój prawa przynależy do zadań uczonych prawników. Prawo pozostaje autonomiczną dyscypliną, systemem zasad, oddzielonych od innych systemów normatywnych regulujących zachowania zarówno poszczególnych jednostek jak i całego społeczeństwa jak przykładowo religia, co z kolei koresponduje z rzymskim oddzieleniem prawa od tego co prawem nie jest. Do spuścizny prawa rzymskiego należy także dominacja prawa prywatnego $\mathrm{w}$ ramach tradycji ius commune, $\mathrm{z}$ akcentem kładzionym na prawo zobowiązań. Ponadto prawo w Europie oparte jest na wartościach, które stawiają osobę w centrum zainteresowania, jako podmiot i intelektualny punkt odniesienia, co jest szczególnie widoczne w idei godności przyznanej człowiekowi jako, że został stworzony na podobieństwo Boga, godności nieodłącznej również zasadzie wolności w prawie rzymskim ${ }^{22}$.

Powszechnie wiadomo, że znajomość prawa rzymskiego jest często warunkiem wstępnym dla znajomości obowiązujących norm prawnych, co więcej rozumienie prawa rzymskiego jest ważne dla krytycznej oceny obowiązującej, jak również proponowanej (przyszłej) legislacji. W przypadku niektórych instytucji prawnych, niejako z konieczności posiłkujemy się terminologią i definicjami oraz opieramy się na normach rzymskiego prawa cywilnego. Taka sytuacja ma miejsce w przypadku międzynarodowych transakcji gospodarczych, wówczas gdy mamy do czynienia z kolizją norm prawnych, gdy prawo obce stosowane jest jako lex fori. Innego przykładu dostarcza unifikacja norm prawnych pomiędzy państwami przynależnymi z jednej strony do tradycji common law, z drugiej zaś kontynentalnymi porządkami prawnymi. Należy ponadto zauważyć, że terminologia prawa rzymskiego nadal dostarcza uniwersalnego języka, tworząc swoisty słownik zarówno dla celów porównawczych jak również dla jednego z najważniejszych problemów konfliktu praw, to jest identyfikacji norm prawnych

22 R. Zimmermann, Roman Law..., s. 366-368. 
lub instytucji. Ius commune to także wspólny zestaw wartości, znajdujący zastosowanie w sporach pomiędzy obywatelami przynależnymi do różnych państw. Ius commune odegrało również istotną rolę w rozwoju nowoczesnego prawa międzynarodowego - ważna kwestia z uwagi na obecne tendencje w kierunku unifikacji praw. Wspólny język prawa rzymskiego pozwalał na przyjmowanie stosunkowo jednolitych statutów, stanowiących podstawę organizacji międzynarodowych, i tym samym umożliwiając ich dalszy rozwój. Użyteczność prawa rzymskiego nie ogranicza się tylko do bezpośredniego wpływu na zawartość nowoczesnych systemów prawnych, bowiem prawo rzymskie, w szczególności zaś decyzje klasycznych jurystów są nierzadko kamieniem probierczym dla testowania wielu kwestii mających wpływ na ogólną teorię prawa ${ }^{23}$.

Szukając śladów wpływów na gruncie europejskim można przywołać rezolucje Parlamentu Europejskiego, które miały na celu stopniową unifikację prawa prywatnego, mianowicie: rezolucja z $1989 \mathrm{r}$. wzywająca państwa członkowskie do harmonizacji prawa prywatnego, w tym do opracowania Common European Code of Private Law ${ }^{24}$; rezolucja z 1994 r. $^{25}$, która odwoływała się do Principles of European Contract Law wypracowanych przez Lando Commission on European Contract Law ${ }^{26}$; rezolucja z 2001 r., dotycząca zbliżania prawa cywilnego i handlowego państw członkowskich ${ }^{27}$; rezolucja z 2003 r. dotycząca europejskiego prawa umów ${ }^{28}$; a także rezolucja z 2008 r. dotycząca wspólnych ram odniesienia dla europejskiego prawa umów ${ }^{29}$.

${ }^{23}$ F. WIEACKER, The Importance..., s. 279-281.

${ }^{24}$ O.J. C 158, 26.6.1989, s. 400.

${ }^{25}$ O.J. C 205, 25.7.1994, s. 518.

${ }^{26}$ Commission on European Contract Law, 1994 http://www.jus.uio.no/lm/ eu.contract.principles.part1.1995 The Principles of European Contract Law 1998, Parts I and II, European Union (completed and revised) http://www.jus.uio.no/lm/ eu.contract.principles.1998/toc.html The Principles of European Contract Law 2002 (Parts I, II, and III) http://www.jus.uio.no/lm/eu.contract.principles.parts.1.to.3.2002
${ }^{27}$ O.J. C 140 E, 13.6.2002, s. 538.
${ }^{28}$ O.J. C 76 E, 25.3.2004, s. 95.
${ }^{29}$ O.J. C 295 E, 4.12.2009, s. 31. 
Należy zauważyć, że standaryzacja europejskiego prawa prywatnego ma miejsce już teraz, przy czym dokonuje się ona przy wykorzystaniu instrumentu prawnego jakim jest dyrektywa, co z kolei pozwala na uniknięcie trudności z jakimi wiązałoby się przygotowywanie wspólnego kodeksu. Harmonizacja prawa obejmuje przede wszystkim takie dziedziny jak: prawo ochrony konsumenta, ochrona własności intelektualnej oraz niektóre typy kontraktów handlowych, a także prawo spółek $^{30}$.

Od czasu Traktatów Rzymskich postępuje stały proces kształtowania się europejskiej struktury instytucjonalno-prawnej, rozwój rynku i wymiana zasobów - procesy które jednakowoż napotykają na poważne przeszkody spowodowane różnicami w krajowych przepisach prawnych. Tak więc, istnieje potrzeba nowego ius commune $\mathrm{w}$ obszarze prawa prywatnego, które zastapiłoby różne prawa narodowe i zmniejszyłoby różnice dzielące porządki prawne państw członkowskich Unii Europejskiej, które są w rzeczywistości w większej mierze różnicami natury formalnej aniżeli materialnej ${ }^{31}$.

Można powiedzieć, że epoka mniej lub bardziej autonomicznych narodowych systemów prawnych powoli dobiega końca. Dyrektywy wydawane przez Unię Europejska, orzecznictwo Trybunału Sprawiedliwości, problemy pojawiające się w związku ze stosowaniem United Nations Convention on Contracts for the International Sale of Goods $(\mathrm{CISG})^{32}$, wpływają na sytuację prawną w Europie, przy czym prawo prywatne w Europie poddawane jest procesowi nabywania na nowo transnarodowego charakteru. Wydaje się, że obecnie zmierzamy w kierunku nowego ius commune, które będzie musiało być zbudowane

${ }^{30}$ B. Periñán, A Romanstic Approach on Unified European Private Law, «Roman Legal Tradition» 1/2002, s. 104-106.

31 Tamże, s. 109; zob. też A.L.M. KeIrSE, European impact on contract law. A perspective on the interlinked contributions of legal scholars, legislators and courts to the Europeanization of contract law, «Utrecht Law Review»7.1/2011, s. 35 i n.

321980 United Nations Convention on Contracts for the International Sale of Goods (CISG), przyjęta na konferencji dyplomatycznej 11 kwietnia 1980 roku, weszła w życie 1 stycznia 1988 roku. http://www.uncitral.org/uncitral/en/uncitral_texts/sale_ goods/1980CISG.html 
w oparciu o wspólne wartości, powszechnie uznane metody prawne, jak również wspólne zasady i wiodące maksymy, ostatecznie kształtowane przez sędziów, ustawodawcę i autorytety naukowe w dziedzinie prawa $^{33}$. Należy nadto zauważyć, że europeizacja czy raczej integracja realizowana w drodze orzeczeń sądowych, pojawiła się w latach 60. Trybunał Sprawiedliwości postrzegany był jako filtr, mediator i moderator umiejscowiony pomiędzy żądaniami jednostek a międzyinstytucjonalnym podejmowaniem decyzjii ${ }^{34}$, przy czym kreatywna rola Trybunału może być (i często jest) przyrównywana do jurysprudencji praetora ${ }^{35}$.

Inną istotną kwestią jest to, że w orzecznictwie Trybunału Sprawiedliwości UE - podobnie jak w orzeczeniach Sądu Najwyższego USA - spotykamy się z bezpośrednim odniesieniem do spuścizny prawa rzymskiego. Przykładem jest orzeczenie z 1969 roku w sprawie Johannes Gerhardus Klomp v Inspektie der Belastingen ${ }^{36}$. Trybunał Sprawiedliwości odwołuje się również do wypracowanych instytucji prawnych jak na przykład qui facit per alium facit per se, jak to miało miejsce w orzeczeniu z 1998 roku The Queen $v$ Commissioners of Customs and Excise, ex parte EMU Tabac SARL ${ }^{37}$, a także in dubio pro

${ }^{33}$ R. Zimmermann, Roman Law, Contemporary Law, European Law, The Civilian Tradition Today, Oxford, New York 2001, s. 108-109.

${ }_{34} \mathrm{~V}$. Antorne, The transnational politics of judicialization, Van Gend en Loos and the making of EU polity, «European Law Journal»16.1/2010, s. 3.

35 Tamże, s. 23.

${ }^{36}$ Orzeczenie TS z 25 lutego 1969 r., Johannes Gerhardus Klomp v Inspektie der Belastingen, case 23-68, (1969) ECR 43, par. 12-14: "In accordance with the principle common to the legal systems of the member states, the origin of which may be traced back to roman law, when legislation is amended, unless the legislature expresses a contrary intention, continuity of the legal system must be ensured".

${ }^{37}$ Orzeczenie TS 2 kwietnia 1998 r., The Queen v Commissioners of Customs and Excise, ex parte EMU Tabac SARL, case C-296/95 (1998) ECR I-1605, par. 28: “In support of their submission, the applicants in the main proceedings argue that the maxim of Roman law qui facit per alium facit per se, meaning that a person acting through an agent must be treated as if he himself were so acting, constitutes a general principle in a number of legal systems, in particular in English law, and must be applied in this case, a fortiori since neither the English version of the Directive nor the 
reo, jak w orzeczeniu $R$ contre Commission des Communautés européennes $\mathrm{z} 1985$ roku $^{38}$.

\section{UWAGI KOŃCOWE}

Prawo rzymskie to nie tylko instytucje wypracowane w drodze praktyki prawnej, lecz także tradycja, kultura, sposób rozumowania i rozwiązywania problemów, oddzielenie tego co jest racjonalne od tego co jest jedynie normą moralną, czy kwestią wiary. Do najważniejszych wartości, które przetrwały do dziś należy zaliczyć racjonalizm, personalizm oraz legalizm. Równie ważne jest podejście do kwestii wolności oraz woli jednostki, co jest szczególnie widoczne w prawie zobowiązań. Ponadto generalizacja zasad i instytucji, pojęć i kryteriów prawa rzymskiego jest charakterystyczną cechą tradycji prawnej. Prawo rzymskie to także spuścizna wcześniejszych tradycji, w szczególności starożytnej Grecji - Grecy dali Europejczykom filozofię, Rzymianom zaś Europa zawdzięcza jeden kompleks kulturowy i prawny, oparty na zasadach, które chroniły życie, własność oraz prawa jednostki. Dominacja Rzymu oznaczała także wspólny język, wspólny system administracyjny oraz wspólną religię, to jest chrześcijaństwo, które rozszerzyło się na całą Europę ${ }^{39}$.

Prawo rzymskie, które poddawane było zmianom, niekiedy też będąc zapomniane, wpływało na kształtowanie się prawa na kontynencie europejskim, w tym również na common law ${ }^{40}$. Co więcej instytucje prawa rzymskiego możemy odnaleźć także na innych kontynentach,

French, Italian, Spanish, German, Dutch or Portuguese versions exclude the possibility of using an agent".

38 Orzeczenie TS z 11 lipca 1985 r., $R$ contre Commission des Communautés européennes, affaires jointes 255 et 256/83 (1985) Recueil de jurisprudence p.2473, par. 32 : “... invoque la violation du principe general in dubio pro reo..."

39 J. McCormick, Europeanism, Oxford 2010, s. 20.

${ }^{40}$ W orzecznictwie sądów amerykańskich, w szczególności Sądu Najwyższego USA pojawiają się często odwołana do instytucji prawa rzymskiego, zob. S.J. AstoRINO, Roman Law in American Law: Twentieth Century Cases of the Supreme Court, «Duquesne Law Review» 40.4/2002, s. 627-654. 
bowiem kodyfikacje europejskie, stanowiły często wzorzec dla rodzimych kodyfikacji. I także dziś, gdy widoczne są tendencje zmierzające do unifikacji prawa czy to w wymiarze globalnym czy tylko regionalnym, instytucje prawa rzymskiego nadal mogą służyć jako swoisty wzorzec. Ponadto jak słusznie zauważa R. Zimmermann europejskie prawo prywatne charakteryzuje bardzo duża różnorodność zasad i rozwiązań, jednakże to jest ta różnorodność, która mieści się w ramach intelektualnej jedności ${ }^{41}$. Z kolei R. Ihering twierdzi ${ }^{42}$ - podobnie jak H. Kupiszewski ${ }^{43}$ - że Rzym trzykrotnie podyktował światu prawa, trzykrotnie jednocząc narody: dając jedność państwową w Imperium cesarskim, jedność Kościoła, a następnie jedność prawa (ius commune) w średniowiecznej Europie. W procesach konsolidacji, które zdają się postępować w sposób nieunikniony, prawo rzymskie ze swoją ideą unifikująca, ma szansę na odegranie ważnej roli, oferuje bowiem model współżycia narodów według swych praw w jednym, obejmującym całą ludność organizmie.

Ruch europejski wraz z instytucjami jakie stworzył, wzbudził ponowne zainteresowanie prawem rzymskim (dokładniej zaś prawem Justyniańskim), jako prawem starożytnej połączonej Europy, jak również średniowiecznym ius commune, prawem, które przekraczało granice narodowe (będąc wykładane w ten sam sposób i w tym samym języku). Instytucje Unii Europejskiej kształtują nowe ius commune, przy czym różnica sprowadza się zasadniczo do tego, że średniowieczne ius commune było przyjmowane dobrowolnie w uznaniu jego wyższości, podczas gdy nowe ius commune jest narzucane w interesie jedności prawa ${ }^{44}$.

Idea Unii (wcześniej Wspólnoty), pod wieloma względami nie jest niczym nowym, stanowi bowiem przywołanie wcześniejszej jedności prawnej i kulturowej w Europie. Jest także dowodem na to, że kultura i cywilizacja rzymska przetrwała, chociaż w nieco już zmienio-

\footnotetext{
${ }^{41}$ R. Zimmermann, Roman Law, Contemporary Law..., s. 114 i n.

42 R. vON JHERING, op. cit., s. 1.

${ }^{43}$ H. KupISZEwSKI, op. cit., s. 215-216.

44 P. SteIn, op. cit., s. 130.
} 
nej formie. Co więcej idea wspólnej Europy, realizująca się w Unii Europejskiej umożliwia to, że możemy się czuć jednocześnie członkami różnych wspólnot i porządków prawnych, będąc nie tylko obywatelami we własnym kraju lecz także obywatelami Europy, a poprzez promowanie uniwersalnych wartości również obywatelami świata.

\section{Roman LaW and European Legal Culture}

\section{Summary}

The Roman law and the later neo-Roman law (ius commune), underlies the legal systems of the Western world, i.e. the continental system (civil law) and the Anglo-American system (common law). The essential constants of European legal culture, formed also by the Roman law are: personalism, referring to the individual as subject, end and an intellectual point of reference in the law; legalism, meaning not merely the monopoly of the modern legislator to create and change the law, but the need to base decisions about social relationships and conflicts on a general rule of law, whose validity and acceptance does not depend on moral, social and political values or purposes; intellectualism that relates to the particular way in which the phenomenon of law is understood. And even today, when we observe a trend towards the unification of law, whether on global or only a regional scale, the Roman law can still serve as a point of reference. 